\title{
ENGINEERING JOURIIAL
}

Article

\section{Comparison of Turbulence Models for Flow Past NACA0015 Airfoil Using OpenFOAM}

\section{Chakrit Suvanjumrat}

Laboratory of Computer Mechanics for Design (LCMD), Department of Mechanical Engineering, Faculty of Engineering, Mahidol University, Nakhon Pathom 73170, Thailand

E-mail: chakrit.suv@mahidol.ac.th

\begin{abstract}
The open source code software, OpenFOAM, was applied for simulating flow past NACA0015 airfoil. Three economical turbulence models for aerospace applications were selected comprising Spalart-Allmaras model, Wilcox $k-\omega$ model and Menter SST $k-\omega$ model, respectively. The non-dimension $\mathrm{y}^{+}$was used to analyze the near-wall flow. The C-type domain for airfoil simulation was considered for an appropriate dimension to protect the effect of boundary conditions. The zero pressure gradient problem of the pressure-velocity coupling was used an effective algorithm, SIMPLE, for solving. The central differencing, upwind differencing, and linear upwind differencing (LUD) scheme were used to solve the convection-diffusion equation of the flow past airfoil. The simulation results included lift coefficient $\left(\mathrm{C}_{\mathrm{L}}\right)$ and drag coefficient $\left(\mathrm{C}_{\mathrm{D}}\right)$ were obtained from this computational fluid dynamics (CFD) method. The turbulence models had been validated to the physical experiment. The wind tunnel was set up to test the flow past NACA0015 airfoil. The Reynolds number (Re) at 160,000 and 360,000 were controlled in order that the NACA0015 airfoil with the large range angle of attack from 0 to 20 degrees was immersed in the low wind speeds and turbulent flow. The suitable turbulence model was the Menter SST $k-\omega$ model which employed SIMPLE algorithm and LUD scheme for solving. These CFD results lower the stall angle of attack had the average errors of $\mathrm{C}_{\mathrm{L}}$ and $C_{D}$ with were less than $13.15 \%$ and $22.36 \%$, respectively.
\end{abstract}

Keywords: Comparison, turbulence model, NACA0015, airfoil, OpenFOAM.

ENGINEERING JOURNAL Volume 21 Issue 3

Received 5 August 2016

Accepted 17 October 2016

Published 15 June 2017

Online at http://www.engj.org/

DOI:10.4186/ej.2017.21.3.207 


\section{Introduction}

The computational fluid dynamics (CFD) method was referred to analyze the active force that happened on the airfoil. The phenomenon of airflow past airfoil can simulate by computer with advantages for reducing time and cost of the physical experiment. The flow past airfoil simulation was analyzed most in the turbulent region [1-3]. The precise solution of CFD method should be achieved when an appropriate turbulence model was selected. The Reynolds-averaged Navier-Stokes (RANS) equation is often used to describe the turbulent flow on the mean flow gather with CFD techniques. The extra terms of RANS equation, Reynolds stresses, were necessary to develop turbulence models for prediction and obtaining results which was close to the mean flow equation [4]. The turbulence models were classified by number of additional transport equations. The one transport equation, Spalart-Allmaras (S-A) model, was developed to calculate kinematic eddy viscosity parameter which related to the local mean vorticity [5]. The two transport equations comprised of the $k-\varepsilon$ model, $k-\omega$ model and algebraic stress model were used to estimate Reynolds stresses. The $k-\varepsilon$ model focused on effects of the turbulent kinetic energy [6, 7]. In the $k-\omega$ model, the turbulent kinetic energy was the product of a velocity scale and a length scale which happened into the rotational flow structure [8]. The algebraic stress models also were the two transport equations which were approximate Reynolds stresses by computing the eddy viscosity in terms of mixing length [9, 10]. The final group of turbulence models which were classified by the additional transport equations is the Reynolds stress equation model (RSM). It is the most complex turbulence model because there are six or seven transport equations for predicting Reynolds stresses that required the high computer ability and calculating time $[11,12]$.

The wind turbine blade simulation referred to use airfoil which was generated inside the C-type domain for simulation by CFD method. The lift coefficient and drag coefficient were simulation results which used to analyze the wind turbine blade performance $[13,14]$. The flow past airfoil involved very complex phenomena at different length scales which induced by geometry. Many turbulence models were applied to simulate airfoil [15-17]. The transport equations included S-A model [18], Wilcox $k-\omega$ model and Menter shear stress transport (SST) $k-\omega$ model [19] were recommended to use for aerospace applications such as an external aerodynamic simulation or the flow past airfoil simulation. Excepting turbulence model, solution methods for the air flow problem had been affected to the accuracy of simulated results. Solving schemes such as the central differencing (CD), upwind differencing (UD), linear upwind differencing (LUD) and quadratic upstream interpolation for convective kinetics (QUICK) scheme were the basically fluid flow solution methods for the convection-diffusion equation. The semi-implicit method for pressure-linked equations (SIMPLE) was an effective algorithm which also was the solution methods for solving pressurevelocity coupling problem under the steady state condition [20]. Many researchers used commercial CFD software such as ANSYS, FLUENT, and STAR-CD which were contained turbulence models and solution methods for the flow past airfoil simulation [21-23]. Unfortunately they were limited by an expensive license cost and the CFD code development. The Open Source Field Operation and Manipulation (OpenFOAM) software had been used $\mathrm{C}++$ language for CFD code without license cost under GNU General Public License [24]. Moreover, any codes can develop and implement to achieve the precise simulation results. This research would apply turbulence models using OpenFOAM software to determine an appropriate turbulence model for the flow past airfoil simulation. A suitable turbulence model that obtained from this research will be useful to analyze and design the wind turbine blades especially under the low wind speeds in the future works.

\section{Turbulence Models}

In this research, there are three turbulence models comprised of Spalart-Allmaras (S-A) model, Wilcox $k-\omega$ model, and Menter SST $k-\omega$ model which were implemented to simulate the flow past NACA0015 airfoil.

\subsection{Spalart-Allmaras Model}

The S-A model is formed with the transport equation of the kinematic eddy viscoscity $(\tilde{v})$ and is written by:

$$
\frac{\partial(\rho \tilde{v})}{\partial t}+\operatorname{div}\left(\rho \tilde{v} U_{i}\right)=\frac{1}{\sigma_{v}} \operatorname{div}\left[(\mu+\rho \tilde{v}) \nabla \tilde{v}+\rho C_{b 2} \frac{\partial \tilde{v}}{\partial x_{i}} \frac{\partial \tilde{v}}{\partial x_{i}}\right]+\rho C_{b 1} \tilde{v} \widetilde{\Omega}-\rho C_{w 1}\left(\frac{\tilde{v}}{\kappa y}\right)^{2} f_{w}
$$


where

$$
\widetilde{\Omega}=\Omega_{\mathrm{ij}}+\frac{\widetilde{\mathrm{v}}}{(\kappa \mathrm{y})^{2}} \mathrm{f}_{\mathrm{v} 2}
$$

and $\tilde{v}$ is the kinematic eddy viscosity, $\widetilde{\Omega}$ is the local mean vorticity, $\Omega_{i j}$ is the mean vorticity tensor, the function $f_{v 2}=f_{v 2}(\tilde{v} / v)$ and $f_{w}$ are the further wall damping functions, $\mu$ is the dynamics viscosity, $\mathrm{y}$ is the distance to the solid wall. The constants include $\sigma_{v}, C_{b 1}, C_{b 2}$ and $\kappa$ have value of $0.67,0.1355,0.622$ and 0.4187 , respectively.

\subsection{Wilcox $\mathbf{k}-\omega$ Model}

The transport equation for $\mathrm{k}$ and $\omega$ model are written by:

$$
\begin{gathered}
\frac{\partial(\rho \mathrm{k})}{\partial \mathrm{t}}+\operatorname{div}\left(\rho \mathrm{kU} U_{\mathrm{i}}\right)=\operatorname{div}\left[\left(\mu+\frac{\rho \mathrm{k}}{\omega \sigma_{\mathrm{k}}}\right) \nabla \mathrm{k}\right]+2 \frac{\rho \mathrm{k}}{\omega} \mathrm{S}_{\mathrm{ij}} \cdot \mathrm{S}_{\mathrm{ij}}-\frac{2}{3} \rho \mathrm{k} \frac{\partial \mathrm{U}_{\mathrm{i}}}{\partial \mathrm{x}_{\mathrm{j}}} \delta_{\mathrm{ij}}-\beta^{*} \rho \mathrm{k} \omega \\
\frac{\partial(\rho \omega)}{\partial \mathrm{t}}+\operatorname{div}\left(\rho \omega \mathrm{U}_{\mathrm{i}}\right)=\operatorname{div}\left[\left(\mu+\frac{\rho \mathrm{k}}{\omega \sigma_{\omega}}\right) \nabla \omega\right]+2 \rho \gamma_{1} S_{\mathrm{ij}} \cdot \mathrm{S}_{\mathrm{ij}}-\frac{2}{3} \rho \gamma_{1} \omega \frac{\partial \mathrm{U}_{\mathrm{i}}}{\partial \mathrm{x}_{\mathrm{j}}} \delta_{\mathrm{ij}}-\beta_{1} \rho \omega^{2}
\end{gathered}
$$

where

$$
\mathrm{S}_{\mathrm{ij}}=\operatorname{div} \mathrm{U}_{\mathrm{i}}
$$

and $k$ is the turbulent kinematic energy, $\omega$ is the turbulent frequency, $\mu$ is the dynamics viscosity, $\mathrm{y}$ is the distance to the solid wall. The constants include $\sigma_{k}, \beta^{*}, \sigma_{\omega}, \gamma_{1}$ and $\beta_{1}$ have value of $2.0,0.09,2.0,0.553$ and 0.075 , respectively.

\subsection{Menter SST k - $\boldsymbol{\omega}$ Model}

The Menter SST $k-\omega$ had been developed from the Wilcox $k-\omega$ to precise simulation results on the boundary layer. Two equations of the Menter SST $k-\omega$ model can be written by:

$$
\begin{gathered}
\frac{\partial(\rho \mathrm{k})}{\partial \mathrm{t}}+\operatorname{div}\left(\rho \mathrm{k} U_{\mathrm{i}}\right)=\operatorname{div}\left[\left(\mu+\frac{\rho \mathrm{k}}{\omega \sigma_{\mathrm{k}}}\right) \nabla \mathrm{k}\right]+2 \frac{\rho \mathrm{k}}{\omega} \mathrm{S}_{\mathrm{ij}} \cdot \mathrm{S}_{\mathrm{ij}}-\frac{2}{3} \rho \mathrm{k} \frac{\partial \mathrm{U}_{\mathrm{i}}}{\partial \mathrm{x}_{\mathrm{j}}} \delta_{\mathrm{ij}}-\beta^{*} \rho \mathrm{k} \omega \\
\frac{\partial(\rho \omega)}{\partial t}+\operatorname{div}\left(\rho \omega U_{i}\right)=\operatorname{div}\left[\left(\mu+\frac{\rho k}{\omega \sigma_{\omega 1}}\right) \nabla \omega\right]+2 \rho \gamma_{2} S_{i j} \cdot S_{i j}-\frac{2}{3} \rho \gamma_{2} \omega \frac{\partial U_{i}}{\partial x_{j}} \delta_{i j} \\
-\beta_{2} \rho \omega^{2}+2 \frac{\rho}{\omega \sigma_{\omega 2}} \frac{\partial k}{\partial x_{k}} \frac{\partial \omega}{\partial x_{k}}
\end{gathered}
$$

where $k$ is the turbulent kinematic energy, $\omega$ is the turbulent frequency, $\mu$ is the dynamics viscosity, y is the distance to solid wall. The constants include $\sigma_{k}, \beta^{*}, \sigma_{\omega 1}, \gamma_{2}, \beta_{2}$ and $\sigma_{\omega 2}$ have value of 1.0, 0.09, 2.0, 0.44, 0.083 and 1.17 , respectively.

\section{Discretization}

The flow past airfoil simulation has been governed by the general transport equation as written by the following form:

$$
\frac{\partial(\bar{\rho} \widetilde{\varnothing})}{\partial \mathrm{t}}+\operatorname{div}\left(\bar{\rho} \widetilde{\varnothing} \widetilde{\mathrm{U}}_{1}\right)=\operatorname{div}(\Gamma \nabla \widetilde{\varnothing})-\operatorname{div}\left(\overline{\bar{\rho} u_{1}^{\prime} \dot{\varphi}}\right)+S_{\varnothing}
$$

where $\bar{\rho}$ is the time average of density, $\widetilde{\emptyset}$ is the time average of general variable, $\dot{\varphi}$ is the fluctuating scalar, $\Gamma$ is diffusion coefficient, $S_{\varnothing}$ is the source term.

Discretization with the finite volume method (FVM) refers to used grid or cell structure which is flexible to generate on the curvature domain as illustrated in Fig. 1. The interested cell had centre node $P$, while the neighbor cells had centre node $N B_{i}$. The distance between node $P$ and $N B_{i}$ is equal to $\Delta X_{i}$. The faces of $\mathrm{P}$ cell which had outer normal direction had been shared around with $N B_{i}$ cell.

In the steady state condition, the transient term is zero. The convection term, $\operatorname{div}\left(\bar{\rho} \widetilde{\emptyset} \widetilde{U}_{l}\right)$, and diffusion term, $\operatorname{div}(\Gamma \nabla \widetilde{\varnothing})$, can be discretized by using CD, UD and LUD scheme which have more detail in Versteeg and Malalasekera [25]. The Reynold stresses, $\overline{\bar{\rho} u_{\imath}^{\prime} \dot{\varphi}}$, are predicted by turbulence models which also using CD, UD and LUD scheme for the convection-diffusion term of the additional transport equations. 


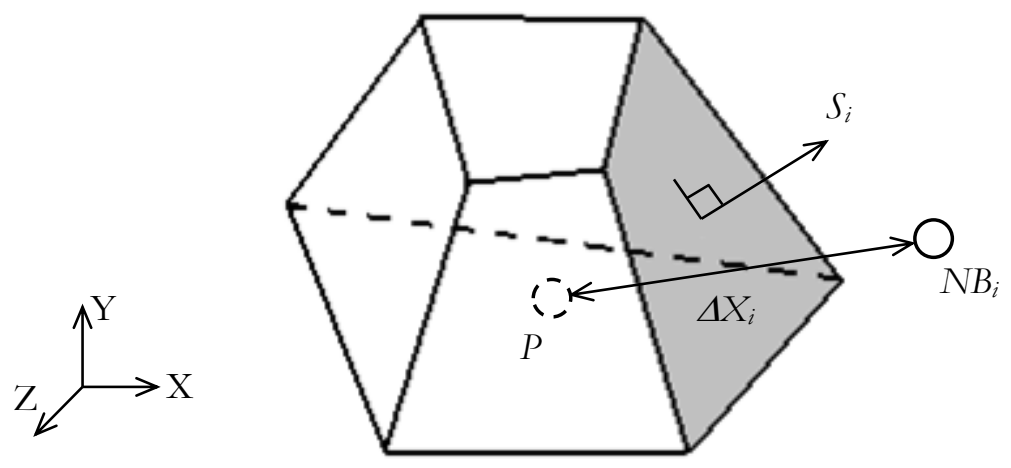

Fig. 1. The grid or cell structure of the finite volume method.

The SIMPLE algorithm is effective for steady state problem starting by assuming guessed pressure into the discretized momentum equations as giving by:

$$
\mathrm{a}_{\mathrm{P}} \mathrm{u}_{\mathrm{P}}^{*}=\sum_{\mathrm{nb}} \mathrm{a}_{\mathrm{nb}} \mathrm{u}_{\mathrm{nb}}^{*}-\Delta \mathrm{A}_{\mathrm{u}}\left(\mathrm{p}_{\mathrm{I}+1}^{*}-\mathrm{p}_{\mathrm{I}-1}^{*}\right)+\mathrm{S}_{\emptyset} \Delta \forall_{\mathrm{u}}
$$

where $a_{P}$ is the interested cell coefficient, $u_{P}^{*}$ is the guessed velocity of an interesting velocity cell, $a_{n b}$ is the neighbor cell coefficient, $u_{n b}^{*}$ is the guessed velocity of a neighbor velocity cell, $\Delta A_{u}$ is the velocity cell area, $p_{I+1}^{*}$ is the guessed pressure at a forward cell of an interesting pressure cell, $p_{I-1}^{*}$ is the guessed pressure at a backward cell of an interesting pressure cell, $\Delta \forall_{u}$ is the velocity cell volume. Notice that, the bar and tilde over parameters had been deleted to be simply for writing equations.

The guessed velocities which are solved by the previous momentum equation have been substituted into the pressure correction equation as given by:

$$
\mathrm{a}_{\mathrm{P}} \dot{\mathrm{P}}_{\mathrm{P}}=\sum_{\mathrm{nb}} \mathrm{a}_{\mathrm{nb}} \hat{\mathrm{P}}_{\mathrm{nb}}-\Delta \mathrm{u}_{\mathrm{P}}^{*}
$$

where $P_{P}$ is the correction pressure of the interesting pressure cell, $\dot{P}_{n b}$ is the correction pressure of the neighbor pressure cell, $\Delta u_{P}^{*}$ is the difference of guessed velocity.

The pressure and velocity which obtain from the SIMPLE algorithm are used the pressure and velocity equation as written by:

where

$$
\begin{aligned}
& \mathrm{p}_{\mathrm{P}}=\mathrm{p}_{\mathrm{P}}^{*}+\hat{\mathrm{P}}_{\mathrm{P}} \\
& \mathrm{u}_{\mathrm{P}}=\mathrm{u}_{\mathrm{P}}^{*}+\mathrm{u}_{\mathrm{P}}
\end{aligned}
$$

$$
\mathrm{u}_{\mathrm{P}}=\frac{\Delta \mathrm{A}_{\mathrm{u}}}{\mathrm{a}_{\mathrm{P}}} \Delta \hat{\mathrm{P}}_{\mathrm{P}}
$$

and $u_{P}$ is the correction velocity of the interesting velocity cell. The correction pressure and velocity will be close to zero after the iterative steps of the SIMPLE algorithm. The under-relaxation is necessary to use for reducing the susceptibility of divergence results. The improved pressure and velocity are obtained from:

$$
\begin{gathered}
\mathrm{p}_{\mathrm{P}}^{\text {new }}=\mathrm{p}_{\mathrm{P}}^{*}+\alpha_{\mathrm{p}} \dot{\mathrm{P}}_{\mathrm{P}} \\
\mathrm{u}_{\mathrm{P}}^{\text {new }}=\alpha_{\mathrm{u}} \mathrm{u}_{\mathrm{P}}+\left(1-\alpha_{\mathrm{u}}\right) \mathrm{u}_{\mathrm{P}}^{(\mathrm{n}-1)}
\end{gathered}
$$

where $\alpha_{p}$ is the factor of pressure under-relaxation, $\alpha_{u}$ is the velocity under-relaxation factor, $u_{P}^{(n-1)}$ is the previous iteration of velocity, the values of under-relaxation factor are between 0 and 1 .

\section{Airfoil Domain and Boundary Conditions}

The computational domain has been used the C-type domain which has radius $(\mathrm{R})$ and downstream length (L) show in Fig. 2. The length of $\mathrm{L}$ was twice values of $\mathrm{R}$ and had been determined for the convergent and accurate results of the CFD method. The flow is close to the wall influenced by viscous effects which comprise of the distance to the wall, fluid density and viscosity, and shear stress. The size of the nearest cells on airfoil surface are attempted to control by the $\mathrm{y}^{+}$value to support the boundary effects which has equation as given by:

$$
\mathrm{y}^{+}=\frac{\Delta \mathrm{y}_{\mathrm{P}}}{v} \sqrt{\frac{\tau_{\mathrm{w}}}{\rho}}
$$


where $y_{P}$ is the near wall distance (Fig. 3), $v$ is the dynamic viscosity, $\tau_{w}$ is the wall shear stress, $\rho$ is the fluid density.

The boundary condition is inlet flow at the left, top and bottom side of the C-type domain which assigned the uniform velocities. At the right side of domain is outlet flow setting by an atmospheric pressure. The front and back domain are set an empty type of boundary condition. No slip conditions $\left(u_{P}=0\right)$ is set only on the wall of airfoil profile. An incompressible flow was used for air with density $(\rho)$ and a dynamics viscosity $(v)$ of $1.225 \mathrm{~kg} / \mathrm{m}^{3}$ and $1.8375 \times 10^{-5} \mathrm{~kg} /(\mathrm{m} \mathrm{s})$, respectively.

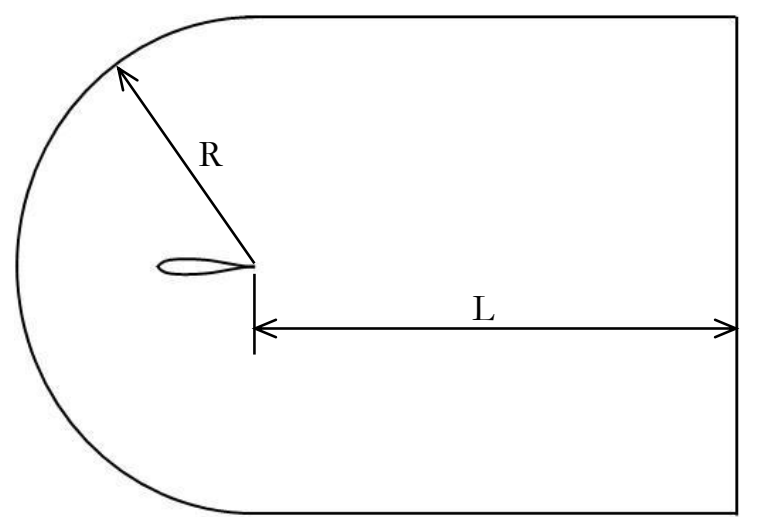

Fig. 2. The C-type domain of the flow past airfoil Fig. 3. The nearest cells of CFD domain of airfoil. simulation.

\section{Experiments}

The wind tunnel model WT300 by Plastrochem Co., Ltd was used to test the flow past airfoil (Fig. 4). The NACA0015 airfoil was installed to test in the wind tunnel. Figure 5 shows the NACA0015 airfoil produced by balsa wood which has the chord length and maximum thickness of 190 and $28.5 \mathrm{~mm}$, respectively. This airfoil has a steel rod which was fixed to the triangular force plate (Fig. 6). The angle of attack (AOA) was adjusted by rotating the steel rod and a locking knob which allowed angles between airfoil and horizontal axis as follows: $0,2,4,6,8,10,12,14,16,18$ and 20 degrees in this research. One beam type load cell and two beam type load cells which were the components of the triangular force plate were respectively used to measure the drag force and lift force. The axial fan which was installed at the end of the wind tunnel had a role to adjust wind flow to keep the Reynolds number (Re) at 160,000 and 360,000. The wind speeds were measured by using a hot wire anemometer (Tenmars; model TM-4001), therefore, the wind speeds at Re of 160,000 and 360,000 were $12.63 \mathrm{~m} / \mathrm{s}$ and $28.42 \mathrm{~m} / \mathrm{s}$, respectively. The force signal from the triangular force plate was recorded along with the time of 5 minutes through RS232 port into a memory device. The lift force $\left(\mathrm{F}_{\mathrm{L}}\right)$ and drag force $\left(\mathrm{F}_{\mathrm{L}}\right)$ which happened on airfoil had been averaged and used for calculating lift coefficient and drag coefficient $[26,27]$. The lift coefficient $\left(\mathrm{C}_{\mathrm{L}}\right)$ and drag coefficient $\left(\mathrm{C}_{\mathrm{D}}\right)$ are given by:

$$
\begin{aligned}
& C_{\mathrm{L}}=\frac{2 \mathrm{~F}_{\mathrm{L}}}{\rho \mathrm{AU}^{2}} \\
& \mathrm{C}_{\mathrm{D}}=\frac{2 \mathrm{~F}_{\mathrm{D}}}{\rho A U^{2}}
\end{aligned}
$$

where $A$ is the characteristic area of airfoil, $\rho$ is the fluid density, $U$ is free stream velocity.

Therefore, the sliding ratio has been defined by:

$$
\mathrm{R}_{\mathrm{S}}=\frac{\mathrm{C}_{\mathrm{L}}}{\mathrm{C}_{\mathrm{D}}}=\frac{\mathrm{F}_{\mathrm{L}}}{\mathrm{F}_{\mathrm{D}}}
$$




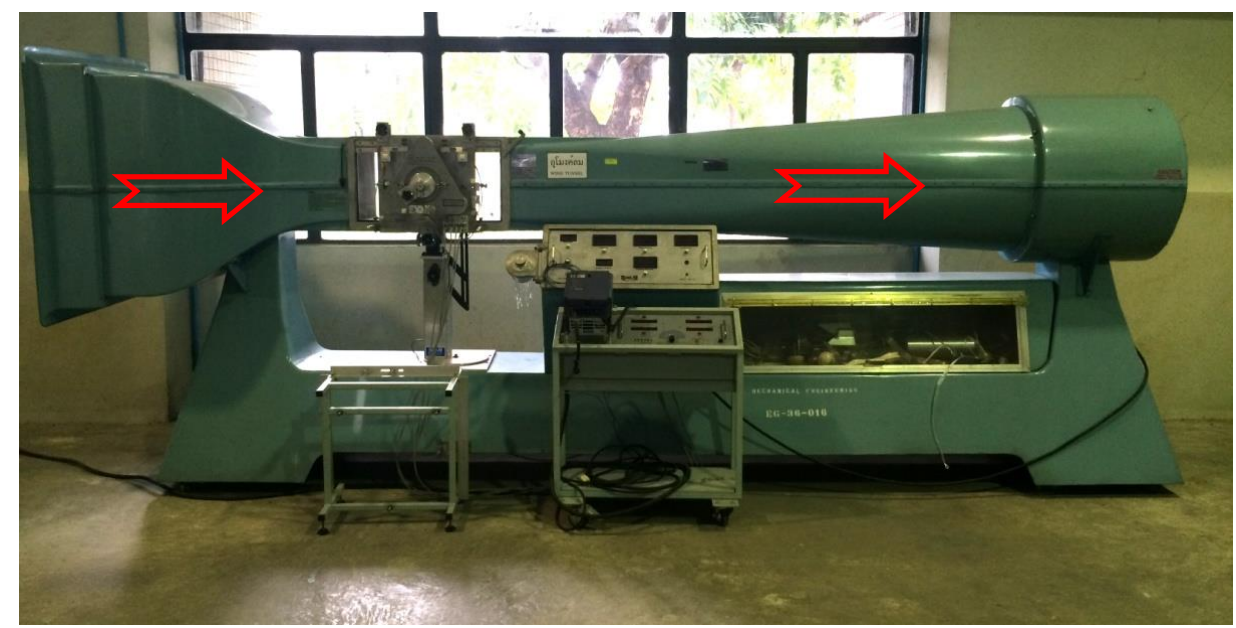

Fig. 4. The wind tunnel model WT300. Notice that, the arrow symbol is the flow direction.

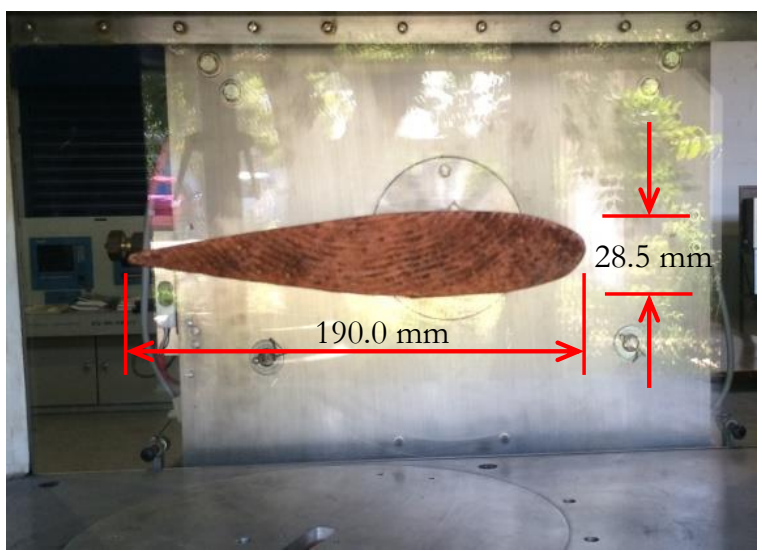

Fig. 5. The NACA0015 airfoil.

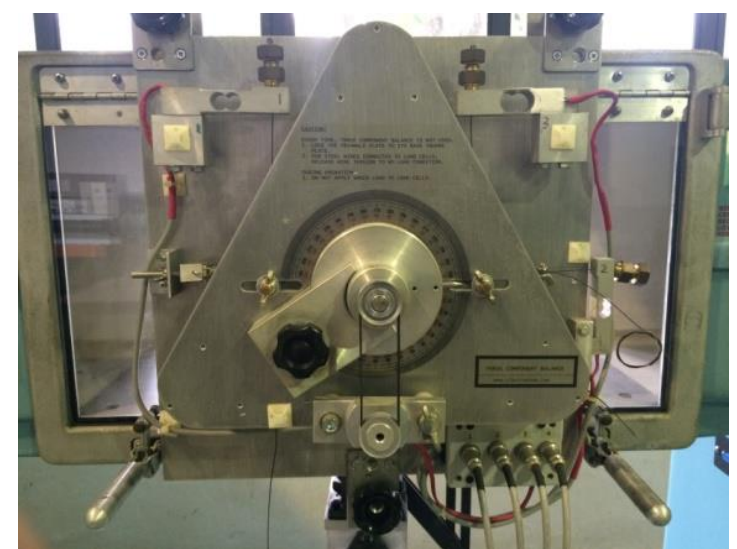

Fig. 6. The triangular force plate.

\section{Results and Discussion}

This section would be described the experimental and simulation results of the flow past NACA0015 airfoil. Three turbulence models comprised of Spalart-Allmaras (S-A) model, Wilcox $k-\omega$ model, and Menter SST $k-\omega$ model were discussed for determining a suitable model of the flow past airfoil simulation.

\subsection{Wind Tunnel Experiment}

The flow past airfoil experiment using the wind tunnel obtains lift coefficient and drag coefficient which are related to the AOA at the Re of 160,000 and 360,000 as shown by graphs in Fig. 7 and Fig. 8, respectively. The low AOA expressed linearly increasing of lift coefficients. The wind speed at Re of 360,000 had more slope of lift coefficient increasing than at Re of 160,000. The maximum lift coefficients were 0.83 and 0.94 which happened at AOA of 10 degrees at the Re of 160,000 and 360,000, respectively. The drag coefficient was distinctively reversed to the lift coefficient starting at the AOA of 12 degrees and 14 degrees for the Re of 160,000 and 360,000, respectively. The critical AOA for the NACA0015 at the Re of 160,000 and 360,000 was 10 degrees which was called "stall angle of attack". Below the stall angle of attack as the AOA increases, the lift coefficient increases. Conversely, above the stall angle of attack as the AOA increases, the air flow is smoothly less on the upper surface of the airfoil and separate from the upper surface. The sliding ratio of the NACA0015 airfoil can be expressed by graph in Fig. 9 and Fig. 10 of the flow past airfoil experiment using the wind tunnel at Re of 160,000 and 360,000, respectively. The high sliding ratio means the time number that the airfoil can generated the lift force more than the drag force. The flow past NACA0015 airfoil with the AOA of 8 degrees at the Re of 360,000 had the sliding ratio more than Re of 160,000 . This ratio can be used to select an extreme AOA and airfoil profile type. The wind turbine blade could be twisted by using the results of the airfoil cross-section test. 


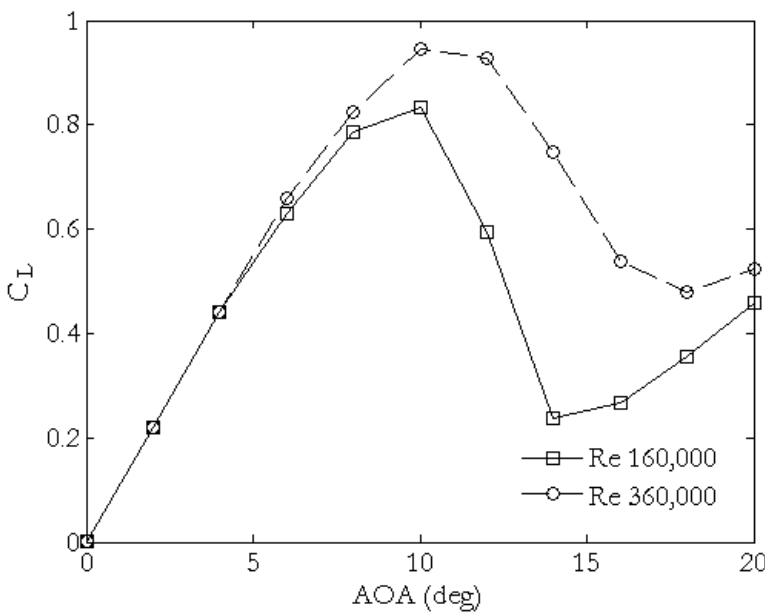

Fig. 7. The lift coefficient $\left(\mathrm{C}_{\mathrm{L}}\right)$ of the NACA0015 airfoil at Re of 160,000 and 360,000.

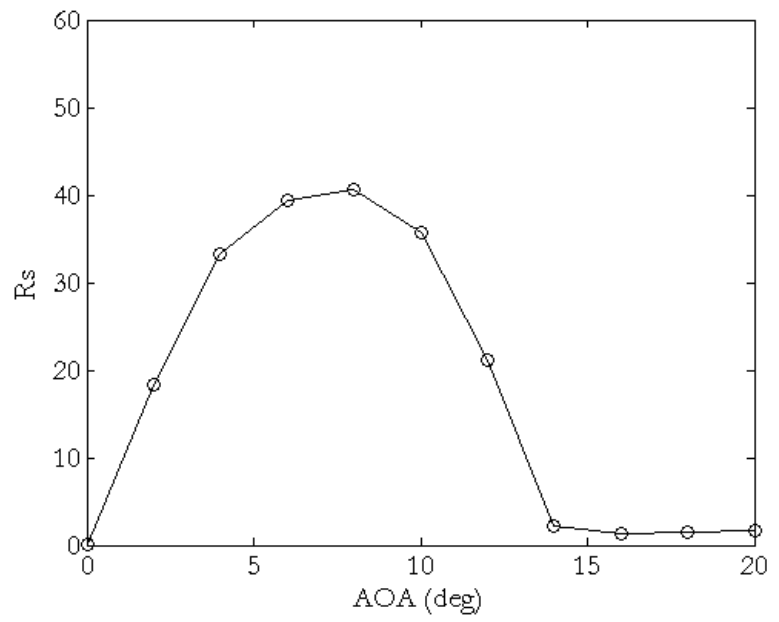

Fig. 9. The sliding ratio (Rs) of the NACA0015 airfoil at Re of 160,000 .

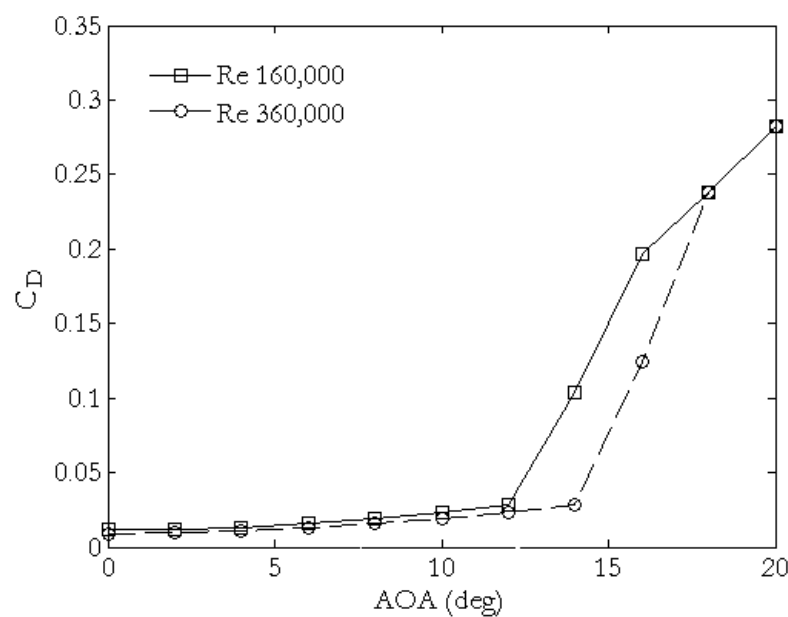

Fig. 8. The drag coefficient $\left(C_{D}\right)$ of the NACA0015 airfoil at $\operatorname{Re}$ of 160,000 and 360,000.

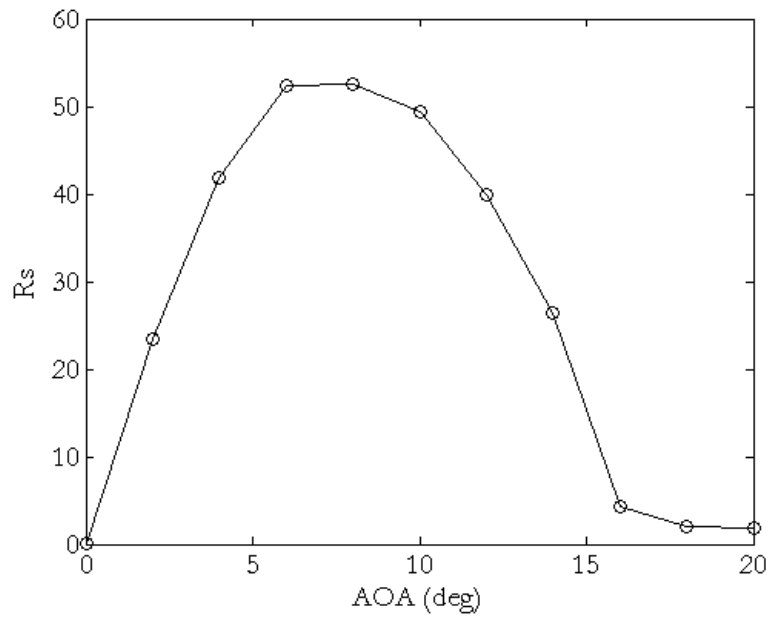

Fig. 10. The sliding ratio (Rs) of the NACA0015 airfoil at Re of 360,000.

\subsection{Grid or Cell Generation}

The CFD domain in this research was obtained by investigating for the accurate results of lift and drag coefficients. Many domain dimensions were selected by investigating the lift coefficients which were variable regarding to values of the downstream length under any turbulence model. Three AOAs below the stall angle of attack were selected to determine the length of the downstream. Figure 11 shows graphs of lift and drag coefficients which are variable regarding to the downstream length. The appropriated dimension for radius and the downstream length gave the accuracy of lift coefficients 13 and 26 times of the chord length, respectively. It respectively seem that lift and drag coefficient simulation results of the downstream length at 28c and 20c were close to the experimental data. Eventually, the average error of coefficients for the downstream length at 26c was less than each other.

Figure 12 illustrates the final C-type domain of the flow past airfoil simulation. The $\mathrm{y}^{+}$of near-wall cells on the upper and lower surface of airfoil had been controlled and achieved values varying between 0.2 and 1.4 that were lower than the satisfied values as equal to +11.63 [28]. The values of $\mathrm{y}^{+}$around airfoil are plotted against distance from leading edge to tailing edge as shown in Fig. 13. The airfoil domain was divided by the hybrid cell dividing method. The structure cells are around the airfoil surface for keeping $\mathrm{y}^{+}$ values lower than +11.63 and the unstructured cells are on the outer of structure cells connecting at the same nodes (Fig. 14). The $\mathrm{y}^{+}$controlling forced the number of nodes around the airfoil were variable from 100 to 600 for determining the independent cells of the simulated domain. The numbers of total cells which give the convergent lift and drag coefficients are determined by relative graphs between cell numbers and coefficients in Fig. 15. The structure cells were 9,000 and the unstructured cells were 49,454 which were the optimum cell numbers of the flow past airfoil simulation domain. Figure 16 shows the final cell 
structure for the flow past NACA0015 airfoil simulation. The finest cells had been generated around surface of the NACA0015 airfoil.

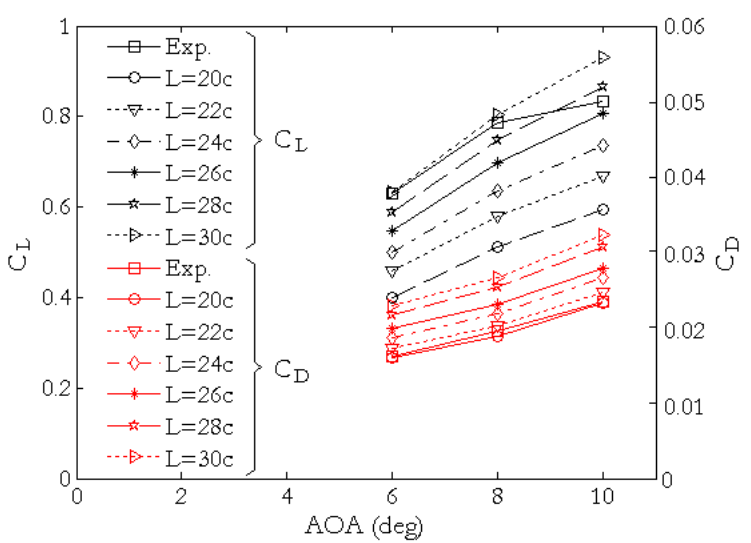

Fig. 11. The lift and drag coefficient regarding to the variable value of the downstream length using the Menter SST $k-\omega$ model.

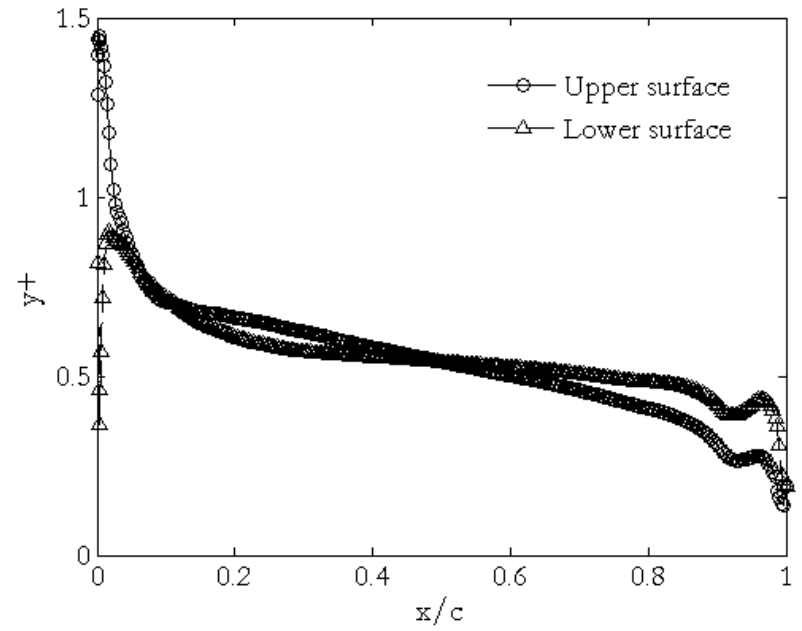

Fig. 13. The variable $y^{+}$values on upper and lower surfaces of NACA0015 airfoil where $\mathrm{x} / \mathrm{c}$ is ratio of distance to chord length.

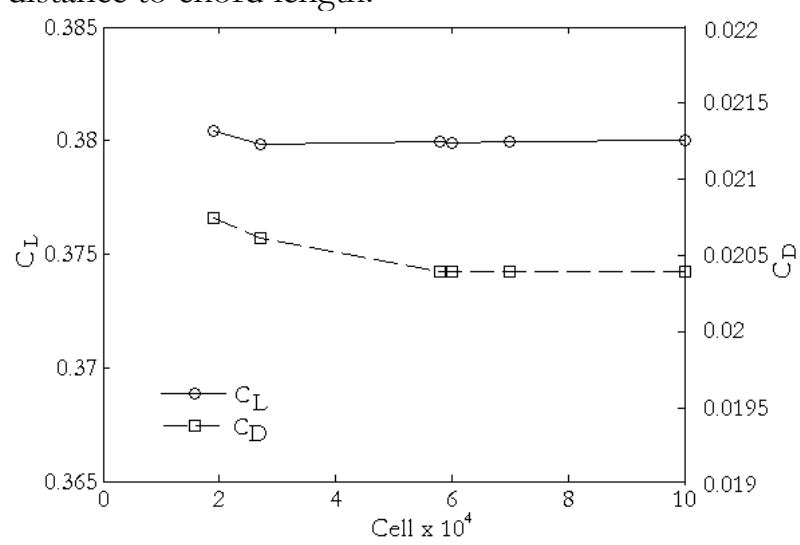

Fig. 15. The lift and drag coefficient regarding on variable numbers of cells.

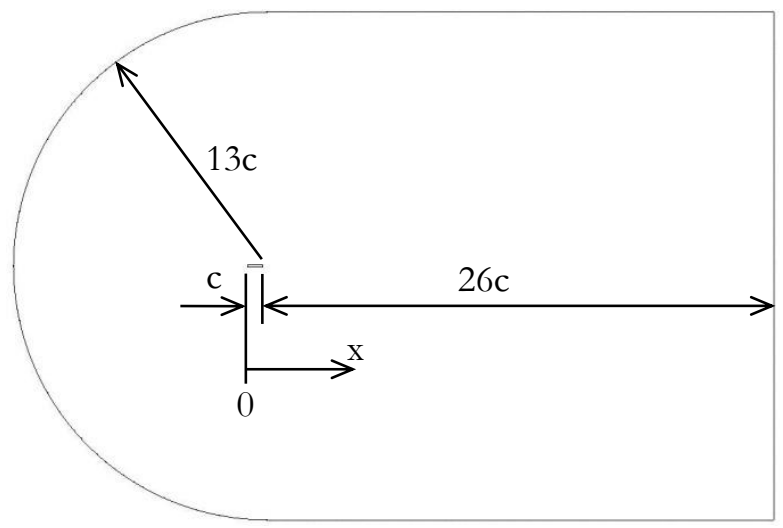

Fig. 12. The C-type domain for flow past NACA0015 airfoil simulation where $c$ is chord length and $\mathrm{x}$ is distance starting at 0 .

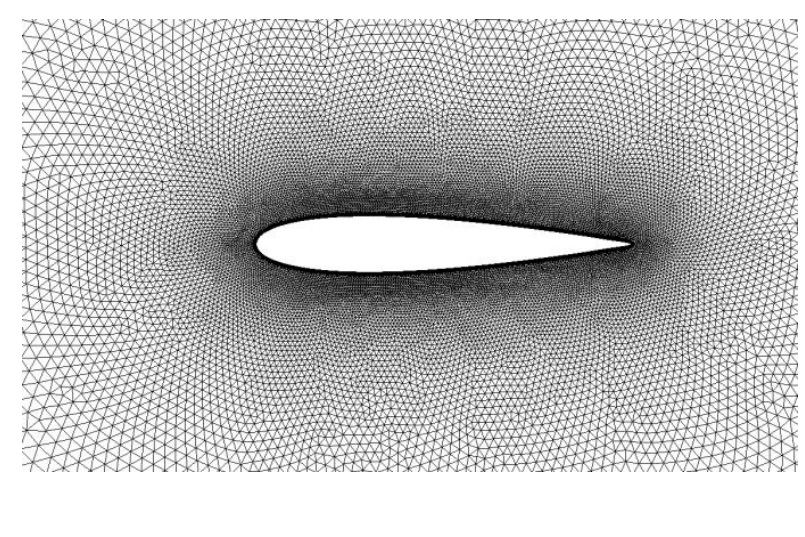

Fig. 14. The near-wall cells for flow past NACA0015 airfoil simulation.

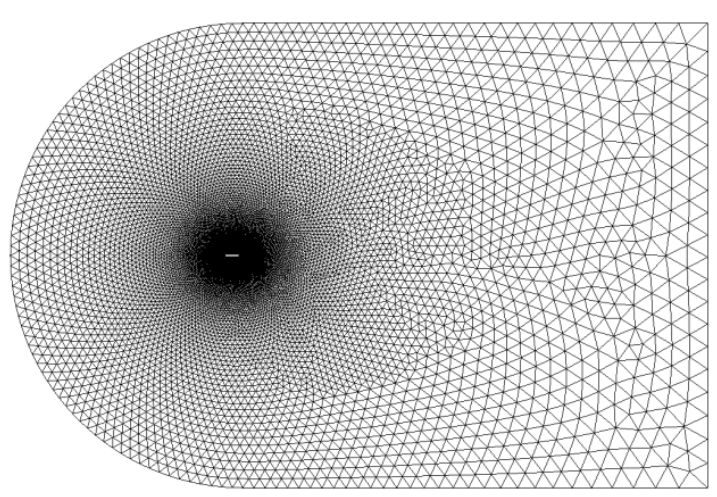

Fig. 16. The final cell structure for flow past NACA0015 airfoil simulation.

\subsection{Airfoil Turbulence Models}

The simulation of flow past NACA0015 airfoil had been performed using S-A model, Wilcox $k-\omega$ model and Menter SST $k-\omega$ model based on the same cell structure domain. The $\mathrm{C}_{\mathrm{L}}$ and $\mathrm{CD}$ results at Re of 
160,000 have been compared to the experimental data as shown in Figs. 17 and 18 while at the Re of 360,000 has been compared and shown in Figs. 19 and 20, respectively. The Menter SST $k-\omega$ model had a trend of the $C_{L}$ and $C_{D}$ in a good agreement with experimental data than the other turbulence models. The critical AOA of the Menter SST $k-\omega$ model gave at 12 degrees which was the little difference from the physical experiment. At the Re of 360,000, the S-A model only gave the stall angle of attack which equal to the Menter SST $k-\omega$ model but the values of coefficient were different from the experiment data more than the Menter SST $k-\omega$ model. The $\mathrm{C}_{\mathrm{D}}$ graph of the Menter SST $k-\omega$ model trended similar to the physical experiment at both Reynolds numbers. The average error of simulations by using turbulence models are described in Table 1. The probable errors of any model caused the downstream length selection which could be reduced by adjusting a suitable value for each model. The average errors of the Menter SST $k-\omega$ model had an absolute value less than the average errors of other turbulence models except the S-A model under the AOA of 0-10 degrees at Re of 160,000. Therefore, the suitable turbulence model for the flow past airfoil simulation was the Menter SST $k-\omega$ model while the Wilcox $k-\omega$ was the unsuitable turbulence model. The S-A might be used for simulating the flow past airfoil because it had one additional transport equation, therefore, it used the least calculating time. Nevertheless, it was not an accuracy model as same as the Menter SST $k-\omega$ model that intended to solve the boundary layer problem.

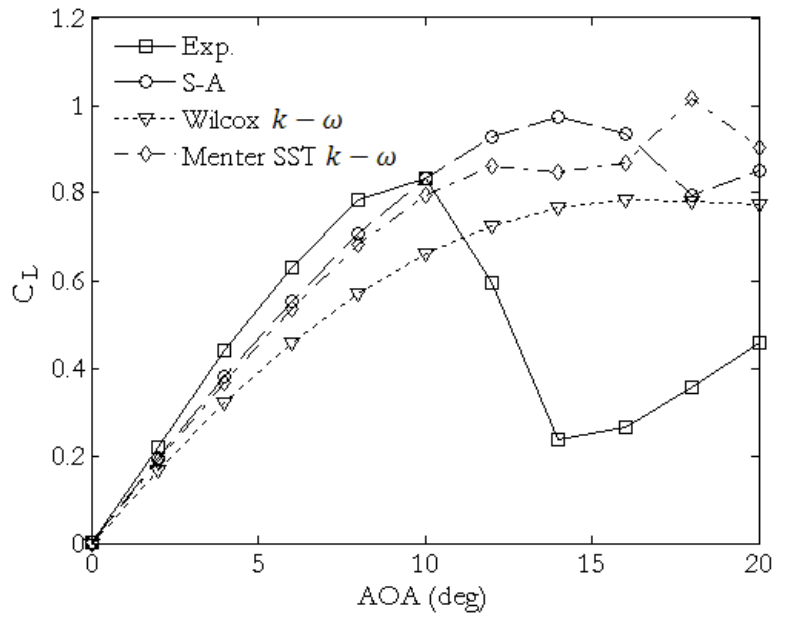

Fig. 17. The lift coefficients by turbulence models at the AOA from 0 to 20 degrees and at the Re of 160,000 .

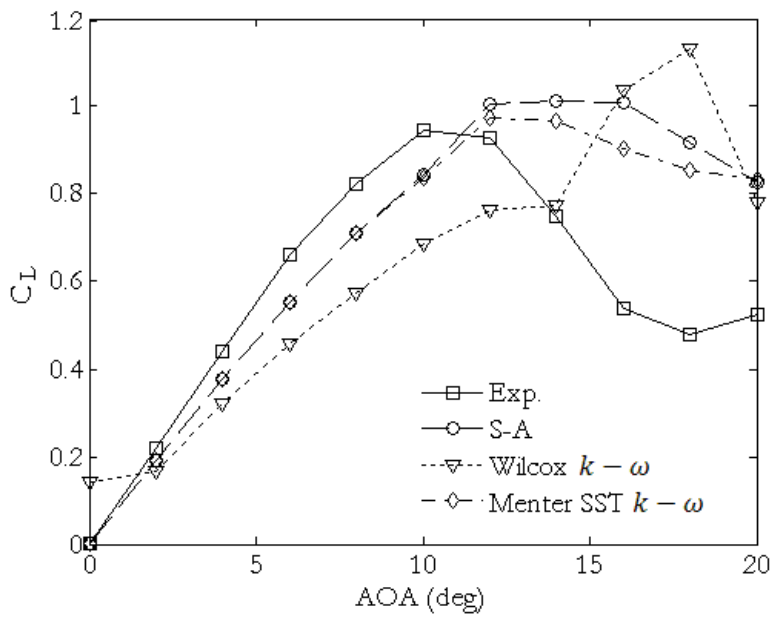

Fig. 19. The lift coefficients by turbulence models at the AOA from 0 to 20 degrees and at the Re of 360,000 .

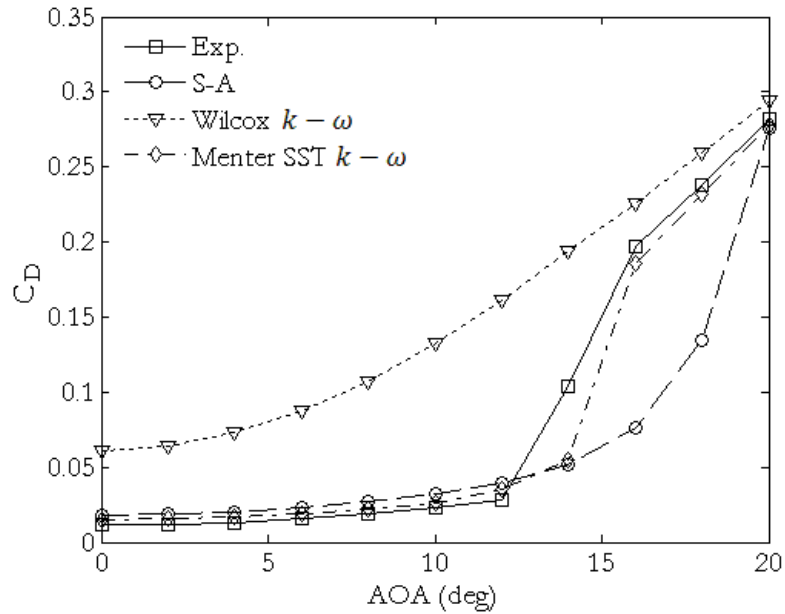

Fig. 18. The drag coefficients by turbulence models at the AOA from 0 to 20 degrees and at the Re of 160,000 .

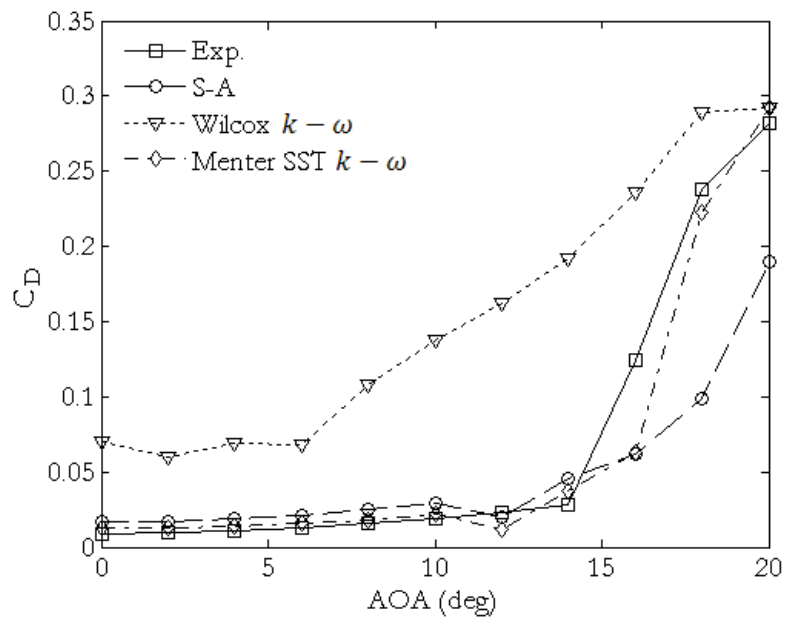

Fig. 20. The drag coefficients by turbulence models at the AOA from 0 to 20 degrees and at the Re of 360,000 . 
Table 1. The average error of turbulence models.

\begin{tabular}{ccccccccc}
\hline & \multicolumn{6}{c}{ The average error of turbulence models (\%) } \\
\cline { 2 - 9 } Model & \multicolumn{3}{c}{ AOA of 0-10 degrees } & \multicolumn{3}{c}{ AOA of 12-20 degrees } \\
\cline { 2 - 9 } & \multicolumn{2}{c}{$\mathrm{Re}=160,000$} & \multicolumn{2}{c}{$\mathrm{Re}=360,000$} & $\mathrm{Re}=160,000$ & $\mathrm{Re}=360,000$ \\
\cline { 2 - 8 } & $\mathrm{C}_{\mathrm{L}}$ & $\mathrm{C}_{\mathrm{D}}$ & $\mathrm{C}_{\mathrm{L}}$ & $\mathrm{C}_{\mathrm{D}}$ & $\mathrm{C}_{\mathrm{L}}$ & $\mathrm{C}_{\mathrm{D}}$ & $\mathrm{C}_{\mathrm{L}}$ & $\mathrm{C}_{\mathrm{D}}$ \\
\hline $\mathrm{S}-\mathrm{A}$ & 9.61 & 46.84 & 13.42 & 68.23 & 165.61 & 39.64 & 56.06 & 43.02 \\
Wilcox $k-\omega$ & 25.56 & 450.68 & 27.83 & 550.08 & 125.48 & 117.46 & 59.75 & 258.56 \\
Menter SST $k-\omega$ & 12.74 & 19.16 & 13.56 & 25.56 & 162.35 & 16.24 & 48.07 & 28.17 \\
\hline
\end{tabular}

S-A model

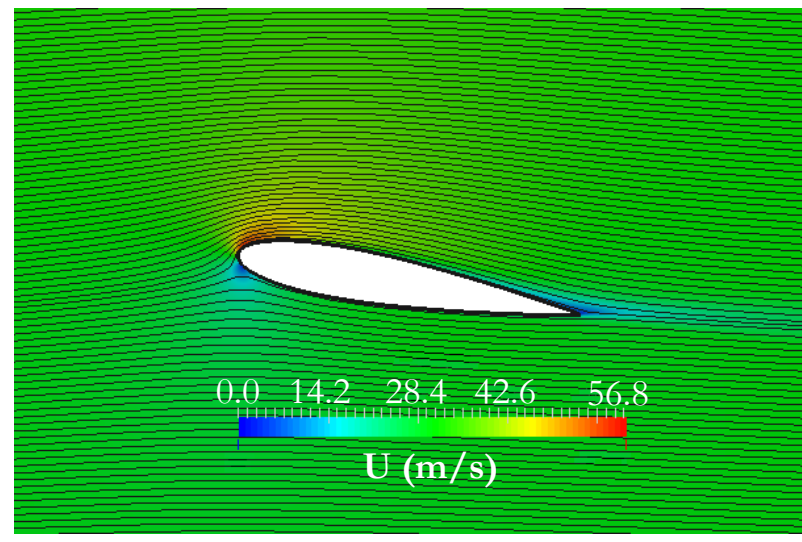

Wilcox $k-\omega$ model

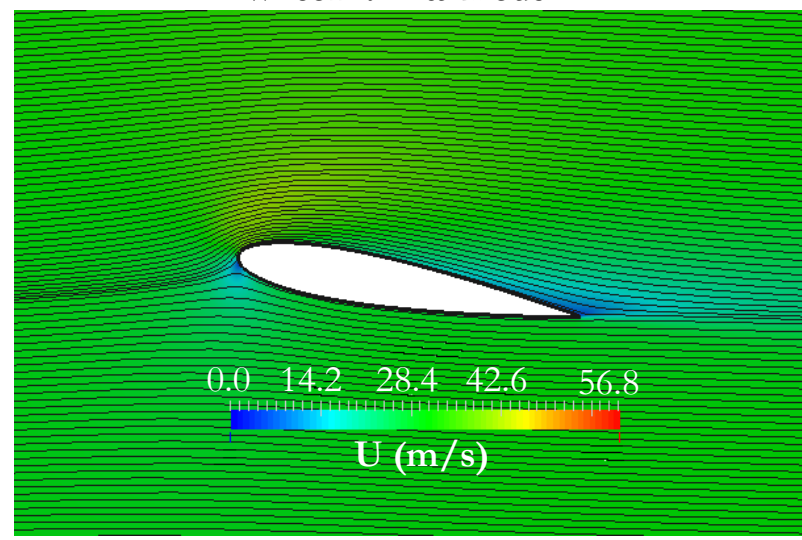

Menter SST $k-\omega$ model

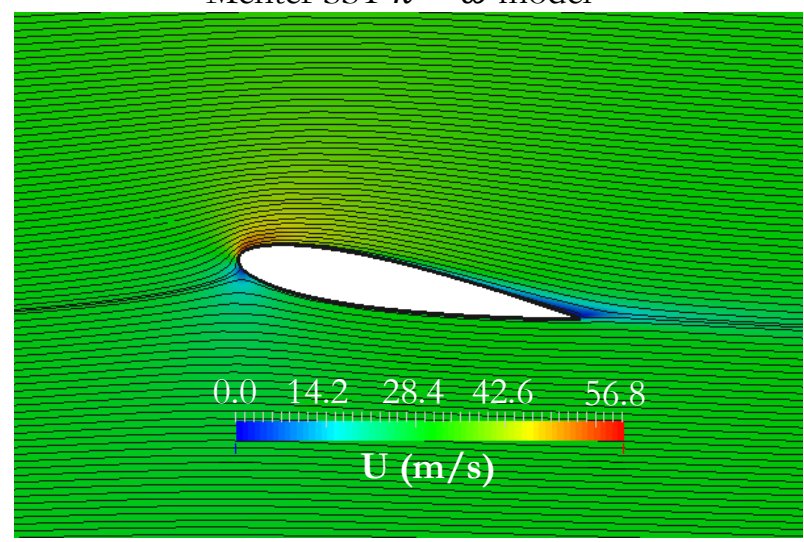

(a)
S-A model

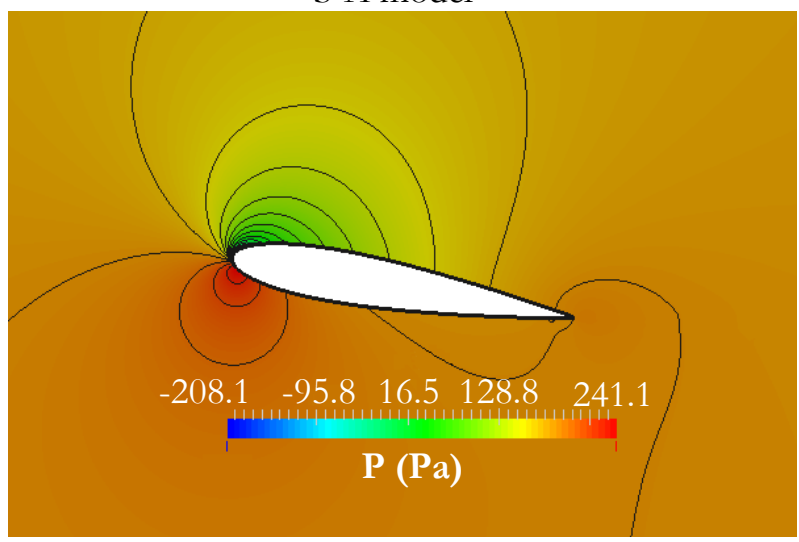

Wilcox $k-\omega$ model

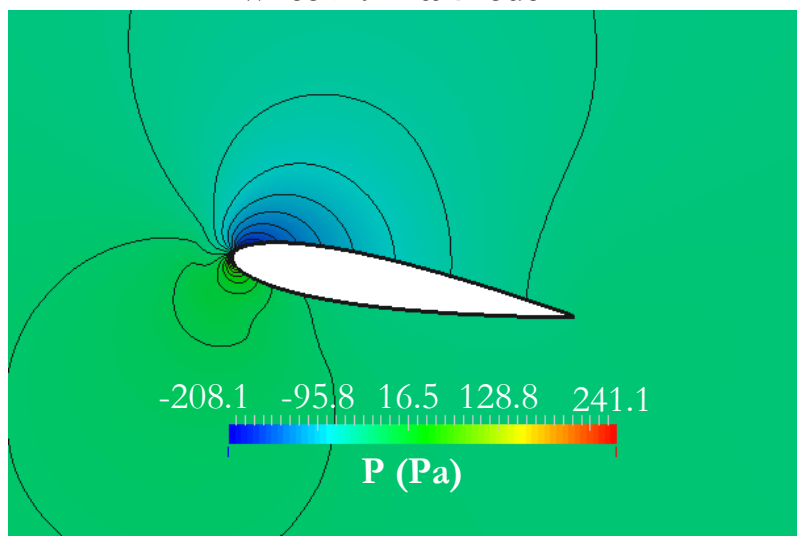

Menter SST $k-\omega$ model

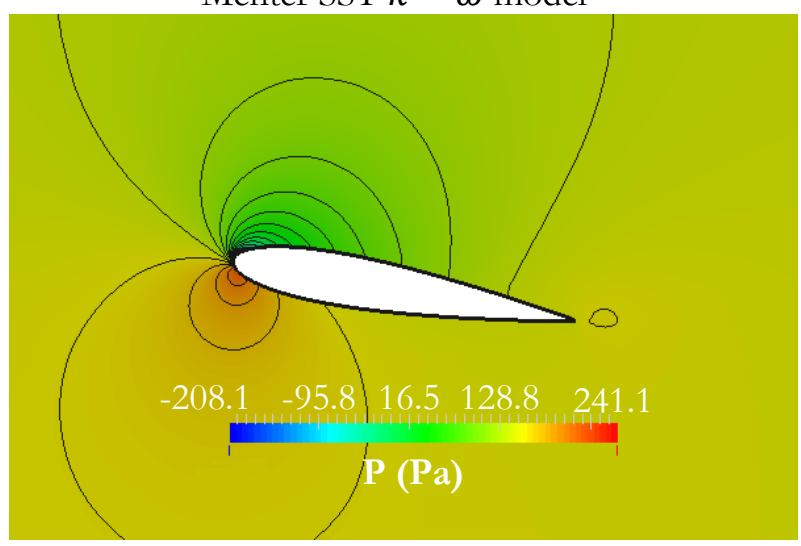

(b)

Fig. 21. The color contour of: (a) velocity and (b) pressure region around the NACA0015 airfoil at AOA of 10 degrees and Re of 360,000 using different turbulence models. 
The CFD results could be expressed by velocity and pressure which occurred around the airfoil. Figure 21 illustrates the velocity and pressure around the NACA airfoil of each turbulence model at AOA of 10 degrees at the Re of 360,000. The solid lines in Fig. 21 (a) are stream lines. The maximum velocity is red (Fig. 21(b)). The maximum pressure region and the minimum pressure region are also red and blue, respectively. The maximum velocity and pressure region happened on the upper surface of leading edge while the velocity was dropped on the trailing edge. Therefore, the lift coefficient which achieved by integrating velocity and pressure on airfoil surface were given the maximum value at this AOA.

\subsection{Solution Methods}

The solution method was employed to determine the good simulation results. The CD, UD and LUD scheme were used to determine $C_{L}$ and $C_{D}$ of the flow past NACA0015 airfoil simulation by using the Menter SST $k-\omega$ model and the upwind algorithm for a turbulence model and the pressure-velocity coupling algorithm, respectively. The $\mathrm{C}_{\mathrm{L}}$ and $\mathrm{C}_{\mathrm{D}}$ of the flow past airfoil simulation at AOA from 0 to 20 and Re of 160,000 which have been used different solution methods are shown in Fig. 22 and Fig. 23, respectively. Subsequently, the $C_{L}$ and $C_{D}$ at Re of 360,000 are shown in Fig. 24 and Fig. 25, respectively. The LUD scheme had results in good agreement with the experimental data. The average errors of the simulation by using different schemes are described in Table 2. The LUD scheme could be performed for determining results as close as experimental data more than other scheme in the AOA range of 0-10 degrees. In the AOA range from 12 to 20, the LUD scheme had the most efficiency to predict the drag coefficient. Even though the UD scheme had accuracy than the LUD scheme for prediction of the lift coefficient at the AOA range of 12-20 degrees, the LUD scheme still had the least average error for the whole range of AOA.

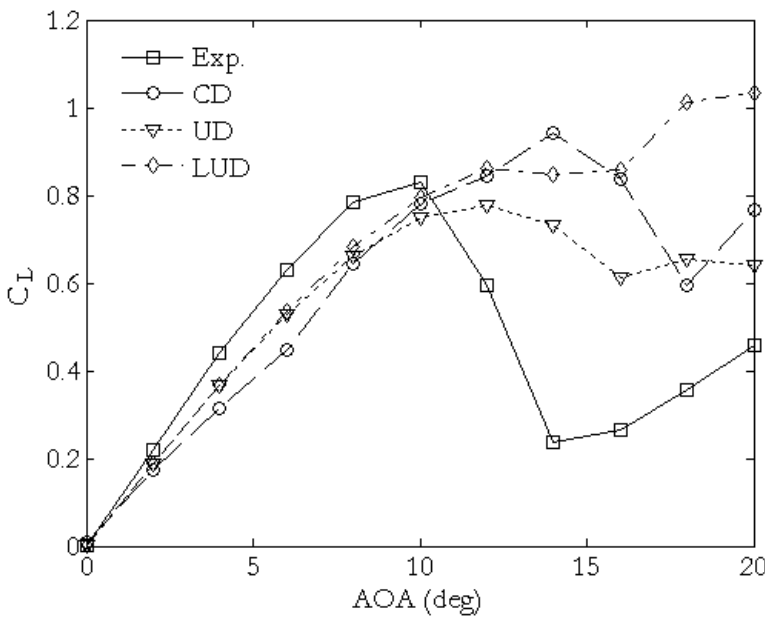

Fig. 22. The lift coefficients using different schemes at the AOA from 0 to 20 degrees and at the Re of 160,000 .

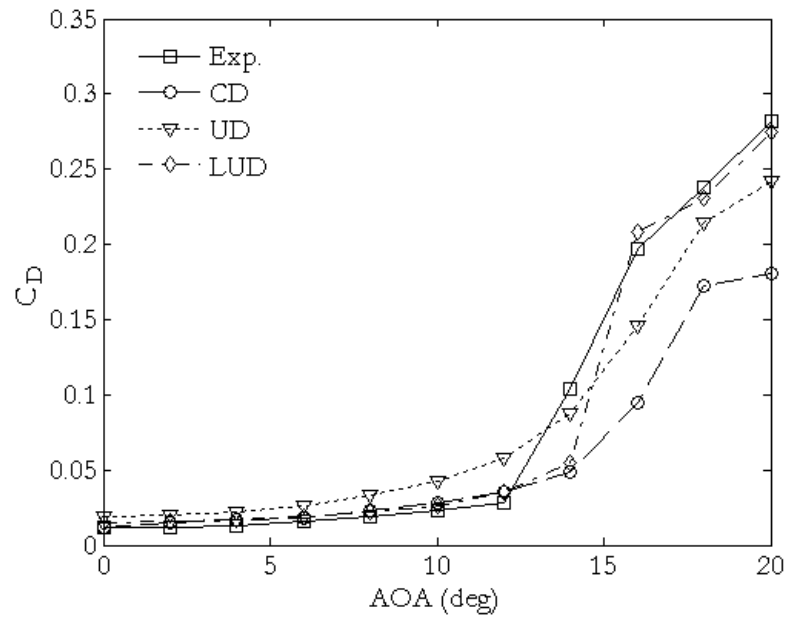

Fig. 23. The drag coefficients using different schemes at the AOA from 0 to 20 degrees and at the Re of 160,000 . 


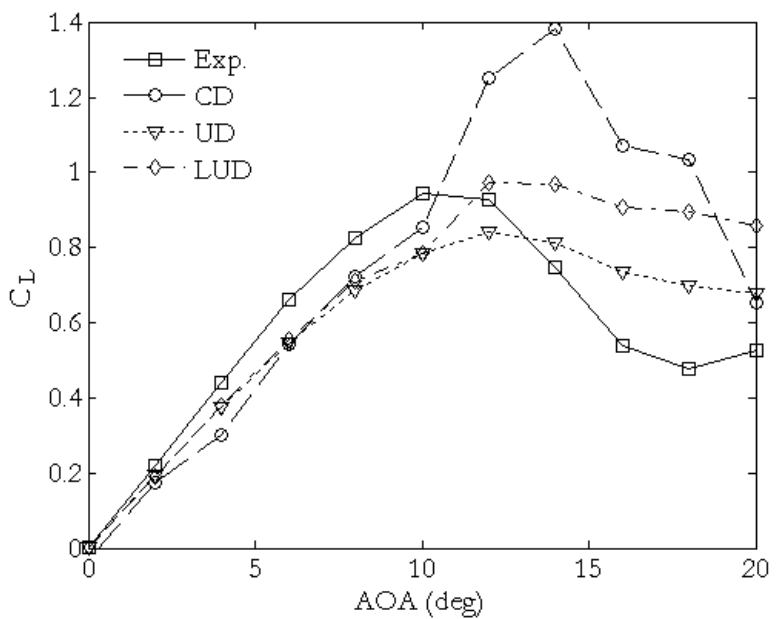

Fig. 24. The lift coefficients using different schemes at the AOA from 0 to 20 degrees and at the Re of 360,000 .

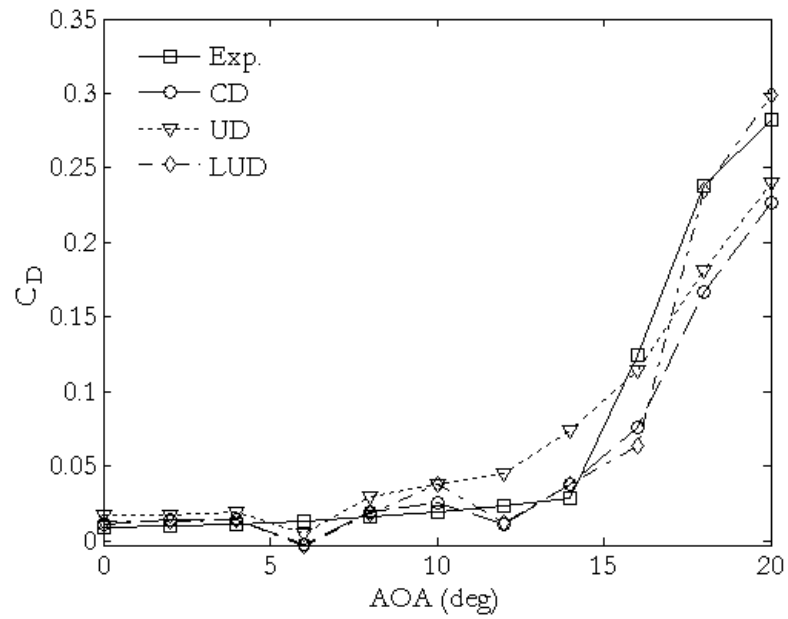

Fig. 25. The drag coefficients using different schemes at the AOA from 0 to 20 degrees and at the Re of 360,000 .

Table 2. The average error of solution methods.

\begin{tabular}{|c|c|c|c|c|c|c|c|c|}
\hline \multirow{4}{*}{ Scheme } & \multicolumn{8}{|c|}{ The average error of schemes $(\%)$} \\
\hline & \multicolumn{4}{|c|}{ AOA of $0-10$ degrees } & \multicolumn{4}{|c|}{ AOA of 12-20 degrees } \\
\hline & \multicolumn{2}{|c|}{$\operatorname{Re}=160,000$} & \multicolumn{2}{|c|}{$\operatorname{Re}=360,000$} & \multicolumn{2}{|c|}{$\operatorname{Re}=160,000$} & \multicolumn{2}{|c|}{$\operatorname{Re}=360,000$} \\
\hline & $\mathrm{C}_{\mathrm{L}}$ & $\mathrm{C}_{\mathrm{D}}$ & $\mathrm{C}_{\mathrm{L}}$ & $\mathrm{C}_{\mathrm{D}}$ & $\mathrm{C}_{\mathrm{L}}$ & $\mathrm{C}_{\mathrm{D}}$ & $\mathrm{C}_{\mathrm{L}}$ & $\mathrm{C}_{\mathrm{D}}$ \\
\hline $\mathrm{CD}$ & 20.43 & 20.74 & 18.21 & 51.75 & 137.69 & 38.82 & 71.78 & 34.74 \\
\hline UD & 14.45 & 70.25 & 15.57 & 85.41 & 98.43 & 34.61 & 25.96 & 59.93 \\
\hline LUD & 12.74 & 19.16 & 13.56 & 25.56 & 162.35 & 16.24 & 48.07 & 28.17 \\
\hline
\end{tabular}

Figure 26 illustrates the separated flow at the Re of 360,000 when the AOA of airfoil is 12 degrees. The small vortex happened on the trailing edge of NACA0015 airfoil. The vortex was expanded and strongly separated flow at the AOA of 18 degrees. The critical AOA or the stall angle of attack was 12 degrees when the SIMPLE algorithm and LUD scheme were employed to solve the Menter SST $k-\omega$ model of the flow past NACA0015 airfoil model. The suitable scheme was the LUD scheme. The CD scheme was very unsuitable scheme for the high velocity or Re above the stall angle of attack.

The sliding ratios for the simulation results of the best model (the SST $k-\omega$ model using SIMPLE algorithm and LUD scheme) are reported by graphs in Fig. 27 and Fig. 28 at Re of 160,000 and 360,000, respectively. For the wind speed at Re of 160,000, the sliding ratio of the CFD was less than the experimental data of $22.44 \%$ while the AOA at the maximum sliding ratios were equally 8 degrees. The best model did not have ability to predict the sliding ratio at high Re. However, the turbulence model could be great for respectively predicting lift and drag coefficient in the whole range of AOA. Therefore, it was intensely enough for studying and designing the wind turbine blade. 


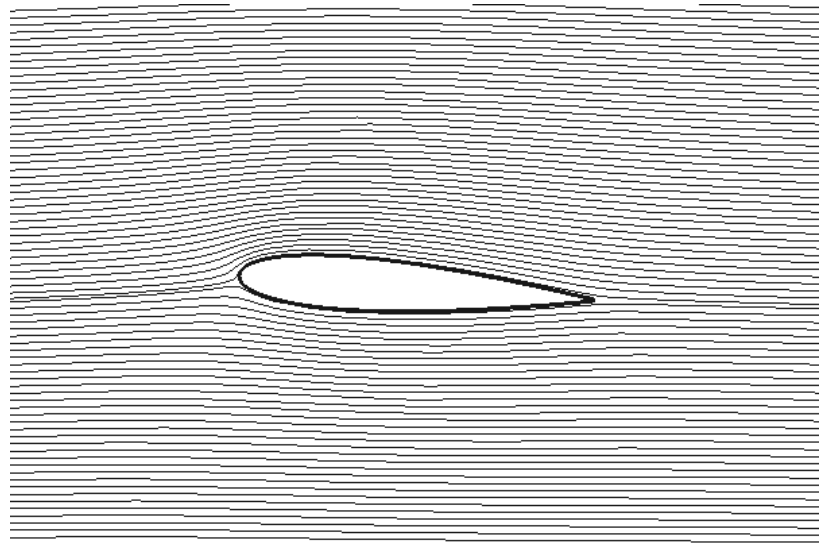

(a)

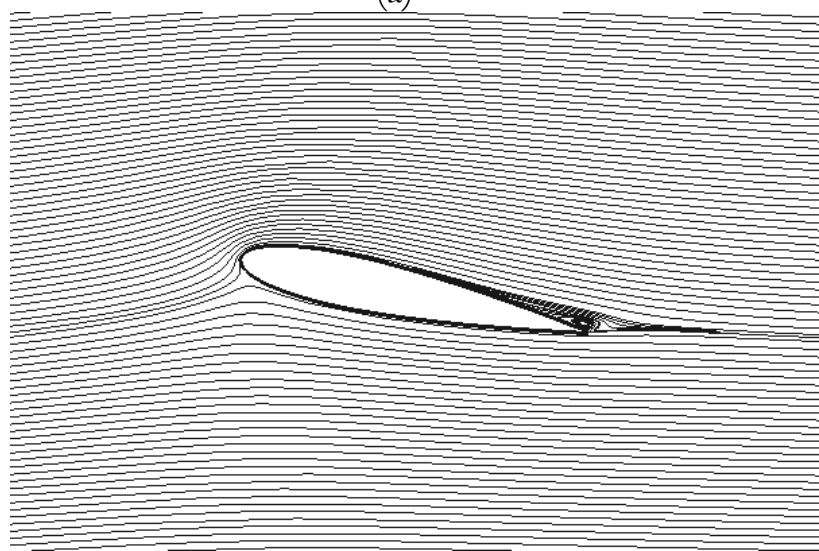

(c)

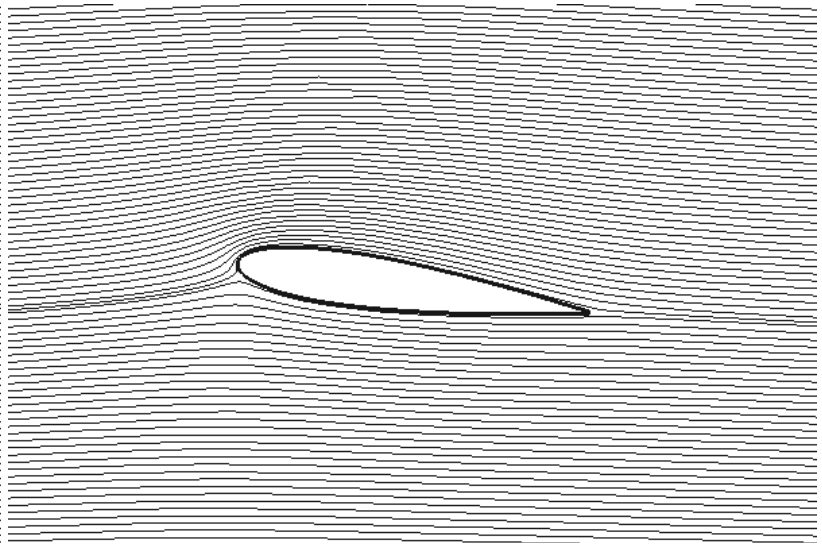

(b)

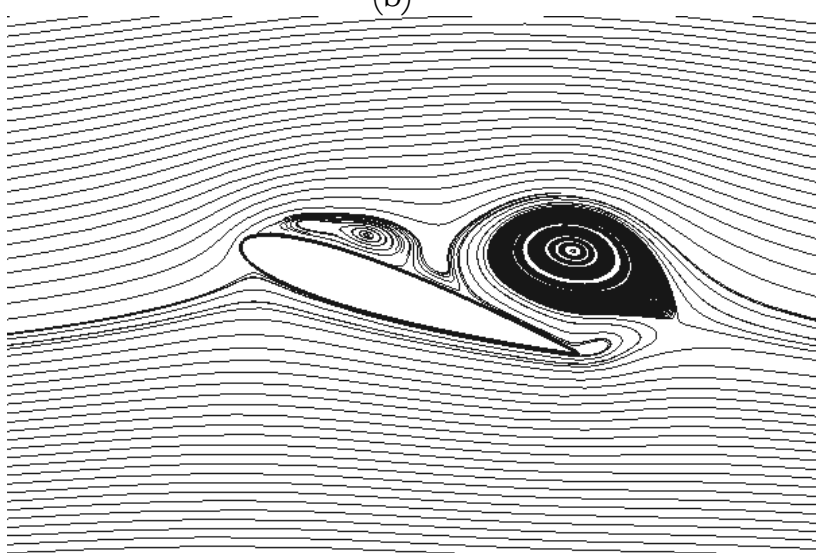

(d)

Fig. 26. The stream line of flow past airfoil simulation using Menter SST $k-\omega$ model and LUD scheme at the AOA of: (a) 4, (b) 8, (c) 12 and (d) 18 degrees and at the Re of 360,000.

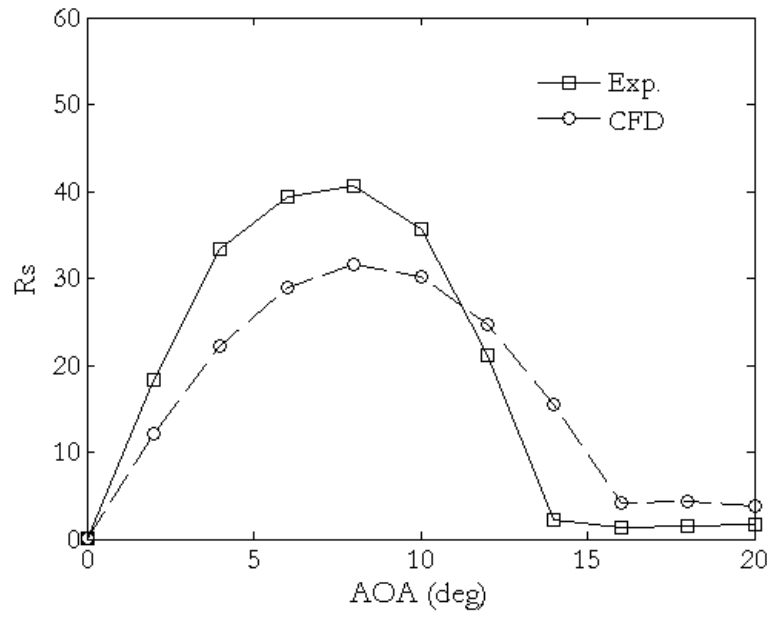

Fig. 27. The comparison of sliding ratio (Rs) for the NACA0015 airfoil at Re of 160,000.

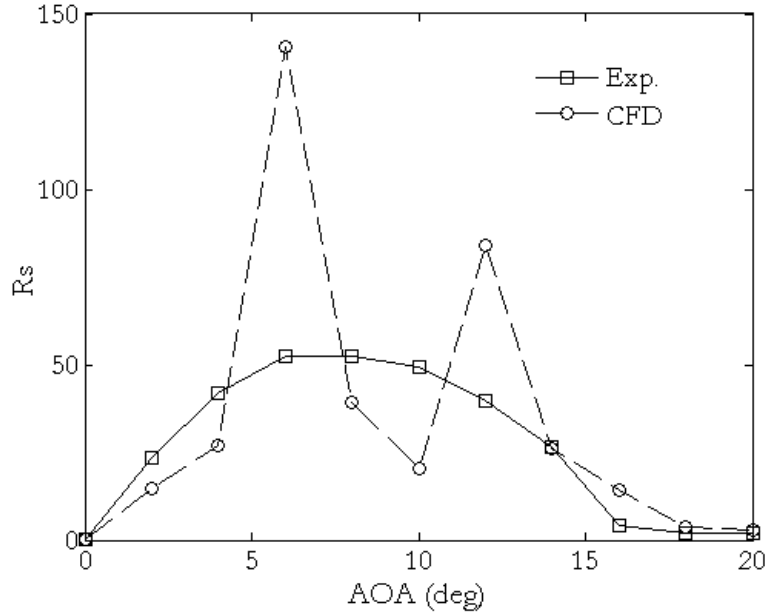

Fig. 28. The comparison of sliding ratio (Rs) for the NACA0015 airfoil at Re of 360,000.

\section{Conclusions}

The turbulence models for the flow past NACA0015 airfoil simulation were implemented and compared to determine the suitable turbulence model for the wind turbine blade design under the low wind speed. Three turbulence models composed Spalart-Allmaras model, Wilcox $k-\omega$ model, and Menter SST $k-\omega$ model which were suggested for the external aerodynamic application employing by generating the CFD code in the open source code CFD software, OpenFOAM. The CFD domain was chosen the C-type domain based on the accuracy results, then the radius and the downstream length of the domain were $13 \mathrm{c}$ and $26 \mathrm{c}$, 
respectively. The C-type domain was constructed by using hybrid cells which composed structure cells around the airfoil surface and unstructured cells connecting at the same nodes outer the structure cells. The structure cell size had been controlled for limit distance from airfoil surface to its node not over than the value that made $\mathrm{y}^{+}$more than +11.63 . The number of cells also had been controlled for the convergence results, therefore, the structure and unstructured cells were 9,000 and 49,454, respectively.

The suitable turbulence model for the flow past NACA0015 airfoil simulation was the Menter SST $k-\omega$ model when compared its lift and drag coefficient with the experimental data. Subsequently, the SST $k-\omega$ model was determined the solution methods which comprised of the pressure-velocity coupling algorithm and the convection-diffusion schemes. The SIMPLE algorithm was chosen for this research regarding to the suggestion for the steady state simulation while three schemes composing UD, UD and LUD scheme were employed to determine the suitable scheme of the turbulence models. The LUD was the suitable scheme to solve the turbulence models because it had the least average error for the coefficients comparison with the experimental data. The simulation results illustrated the stream lines were formed to be a small vortex on the trailing edge at the AOA of 12 degrees, therefore, the maximum lift coefficient happened at this angle. The vortex was expanded and strongly separated flow above the stall angle of attack. The lift coefficients of simulation results reported the critical AOA or the stall angle of attack at 12 degrees which was a little different stall angle of attack by using the physical experiment.

The comparison of turbulence models and solution methods for this research were concluded that the Menter SST $k-\omega$ model with the SIMPLE algorithm and LUD scheme was the suitable turbulence model for simulation flow past NACA0015 airfoil. Consequently, it was recommended for using to study and design airfoil of wind turbines under the low wind speeds in the future work. Particularly, the OpenFOAM software was an excellent software for performing the flow past airfoil simulation without the expensive license cost.

\section{Acknowledgment}

The author wishes to thank our graduate student, Mr. Peerakit Kekina, for supporting the experimental data and simulation data in this research.

\section{References}

[1] P. Bo, Y. Hao, F. Hong, and W. Ming, "Modification of k- $\omega$ turbulence model for predicting airfoil aerodynamic performance," J. Therm. Sci. vol. 24, no. 3, pp. 221-228, Jun. 2015.

[2] D. Kim, G. S. Lee, and C. Cheong, "Inflow broadband noise from an isolate symmetric airfoil interacting with incident turbulence," J. Fluid. Struct., vol. 55, pp. 428-450, Apr. 2015.

[3] P. Svacek and J. Horacek, "Numerical simulation of aeroelastic response of an airfoil in flow with laminar-turbulence transition," Appl. Math. Comput., vol. 267, pp. 28-41, Sep. 2015.

[4] H. K. Versteeg and W. Malalasekera, "Turbulence and its modelling," in An Introduction to Computational Fluid Dynamics: The Finite Volume Method, $2^{\text {nd }}$ ed. Malaysia: Pearson Education Limited, 2007, ch. 3, pp. 40-114.

[5] P. R. Spalart and S. R. Allmaras, "A one-equation turbulence model for aerodynamic flow," AIAA, Seattle, WA, Rep. AIAA-92-0439, 1992.

[6] E. Turgeon, D. Pelletier, J. Borggaard, and S. Etienne, "Application of a sensitivity equation method to the k-E model of turbulence," Optim. Eng. vol. 8, no. 4, pp. 341-372, Dec. 2007.

[7] W. N. Edeling, P. Cinnella, R. P. Dwight, and H. Bijl, "Bayesian estimates of parameter in the k- $\varepsilon$ turbulence model," J. Comput. Phys. vol. 258, pp. 73-94, Dec. 2014.

[8] D. C. Wilcox, "Turbulence energy equation models," in Turbulence Modelling for CFD, $2^{\text {nd }}$ ed. California: ECW Industries Inc., 1994, ch. 4, pp. 73-170.

[9] D. C. Wilcox, "Algebraic models," in Turbulence Modelling for CFD, $2^{\text {nd }}$ ed. California: ECW Industries Inc., 1994, ch. 4, pp. 23-72.

[10] G. Ahmadi, S. J. Chowdhury, W. N. Edeling, P. Cinnella, R. P. Dwight, and H. Bijl, "A ratedependent algebraic stress model for turbulence," Appl. Math. Modelling., vol. 15, pp. 516-524, Oct. 1991.

[11] B. E. Launder, G. J. Reece, and W. Rodi, "Progress in development of Raynolds-stress turbulent closure," J. Fluid Mech., vol. 68, pp. 537-566, 1975. 
[12] V. Bianco, A. Khait, A. Noskov, and V. Alexhin, "A comparison of the application of RSM and LES turbulence models in the numerical simulation of thermal and flow patterns in a double-circuit Ranque-Hilsch vortex tube," Appl. Therm. Eng. vol. 106, pp. 1244-1256, Aug. 2016.

[13] M. A. Sayed, H. A. Kandil, and A. Shaltot, "Aerodynamic analysis of different wind-turbine-blade profiles using finite-volume method," Energ. Converg. Manage., vol. 64, pp. 541-550, Dec. 2012.

[14] C. J. Bai, P. W. Chen, and W. C. Wang, "Aerodynamic design and analysis of a $10 \mathrm{~kW}$ horizontal-axis wind turbine for Tainan, Taiwan," Clean. Techn. Environ. Policy., vol. 18, no. 4, pp. 1151-1166, Apr. 2016.

[15] M. Franke, S. Willin, and F. Thiele, "Assessment of explicit algebraic Reynolds-stress turbulence models in aerodynamic computations," Aerosp. Sci. Technol. vol. 9, no. 7, pp. 573-581, Oct. 2005.

[16] M. Moshfeghi, Y. J. Song, and Y. H. Xie, "Effects of near-wall grid spacing on SST-K- $\omega$ model using NREL phasr VI horizontal axis wind turbine," J. Wind Eng. Ind. Aerod., vol. 107-108, pp. 117-132, Aug.-Sep. 2012.

[17] R. Lanzafame, S. Mauro, and M. Messina, "Wind turbine CFD modeling using a correlation-based transitional model,” Renew. Engrg., vol. 52, pp. 31-39, Apr. 2013.

[18] P. R. Spalart and S. R. Allmaras, "A one equations turbulence model for aerodynamic flows," AIAA, Washington, DC, Rep. AIAA-92-0439, 1992.

[19] F. R. Menter, "Zonal two equations $k-\omega$ turbulence models for aerodynamic flows," AIAA, Washington, DC, Rep. AIAA-93-2906, 1993.

[20] C. J. Greensheilds, "Applications and libraries," in OpenFOAM: The Open Source CFD Toolbox (User Guide Version 3.0.1). UK: OpenFOAM Foundation Ltd., 2015, ch. 3, pp. 69-104.

[21] R. Belamadi, A. Djemili, A. Ilica, and R. Mdouki, "Aerodynamic performance analysis of slotted airfoils for application to wind turbine blades," J. Wind Eng. Ind. Aerod., vol. 151, pp. 79-99, Apr. 2016.

[22] X. Cai, R. Gu, P. Pan, and J. Zhu, "Unsteady aerodynamics simulation of a full-scale horizontal axis wind turbine using CFD methodology," Energ. Converg. Manage., vol. 112, pp. 146-156, Mar. 2016.

[23] M. H. Gardiri, N. L. N. Ibrahim, and M. F. Mohamed, "Performance evolution of for-sided square wind catchers with different geometries by numerical method," Engineering Journal, vol. 17, no. 4, pp. 917, Oct. 2013.

[24] C. J. Greensheilds, "Coppyright notice," in OpenFOAM: The Open Source CFD Toolbox (Programmer's Guide Version 3.0.1). UK: OpenFOAM Foundation Ltd., 2015, pp. 2-6.

[25] H. K. Versteeg and W. Malalasekera, "The finite volume method for convection-diffusion problem," in An Introduction to Computational Fluid Dynamics: The Finite Volume Method, 2nd ed. Malaysia: Pearson Education Limited, 2007, ch. 5, pp. 134-178.

[26] B. R. Munson, D. F. Young, T. H. Okiishi, and W. W. Huebsch "Flow over immersed bodies," in Fundamentals of fluid mechanics, 6th ed. Asia: John Wiley \& Sons, 2010, ch. 9, pp. 461-533.

[27] S. Mathew and G. S. Philip, "Aerodynamics of horizontal axis wind turbines," in Advance in Wind Energy Conversion Technology. Berlin: Springer, 2011, ch. 1, pp. 1-69.

[28] H. K. Versteeg and W. Malalasekera, "Implementation of boundary conditions," in An Introduction to Computational Fluid Dynamics: The Finite Volume Method, 2nd ed. Malaysia: Pearson Education Limited, 2007, ch. 9, pp. 267-284. 